Case Report

\title{
Two Rare Complications in One Patient: Acquired von Willebrand Syndrome Associated with Intracranial Plasmacytoma
}

\author{
H. Auge $\mathbb{D}^{1},{ }^{1}$ C. Yguel, ${ }^{2}$ E. Schmitt, ${ }^{3}$ B. Frotscher, ${ }^{4}$ H. Busby-Venner, ${ }^{2}$ R. Morizot, ${ }^{1}$ \\ C. Moulin, ${ }^{1}$ P. Feugier, ${ }^{1}$ A. Perrot, ${ }^{1}$ and L. Filliatre-Clement $\mathbb{D}^{1}$ \\ ${ }^{1}$ Hematology Department, University Hospital of Nancy, 5 Rue du Morvan, 54500 Vandoeuvre les Nancy, France \\ ${ }^{2}$ Histopathology Department, University Hospital of Nancy, 5 Rue du Morvan, 54500 Vandoeuvre les Nancy, France \\ ${ }^{3}$ Neuroradiology Department, University Hospital of Nancy, 29 Avenue du Maréchal de Lattre de Tassigny, 54035 Nancy, France \\ ${ }^{4}$ Hemostasis Department, University Hospital of Nancy, 5 Rue du Morvan, 54500 Vandoeuvre les Nancy, France
}

Correspondence should be addressed to H. Auge; h.auge@chru-nancy.fr

Received 18 January 2019; Revised 30 June 2019; Accepted 13 August 2019; Published 27 August 2019

Academic Editor: Sudhir Tauro

Copyright (C) 2019 H. Auge et al. This is an open access article distributed under the Creative Commons Attribution License, which permits unrestricted use, distribution, and reproduction in any medium, provided the original work is properly cited.

\begin{abstract}
Here, we describe a rare case of acquired von Willebrand syndrome (VWS) associated with intracranial plasmacytoma. The literature includes reports of a few cases of plasmacytoma with central nervous involvement, but none of them with acquired VWS. Diagnosis was made based on a stereotaxic intracerebral biopsy. During this biopsy, a ventriculoperitoneal shunt was established, which was complicated with abnormal bleeding. Subsequent hemostasis assessment related to hemopathy revealed acquired von Willebrand disease. The patient received induction therapy with bortezomib, thalidomide, and dexamethasone (VTD), followed by high-dose melphalan chemotherapy and autologous stem cell transplantation, and then VTD consolidation, and finally maintenance with lenalidomide. Our patient currently remains in very good partial response without neurological symptoms after 4 months of maintenance. The patient is free of progression 14 months after their original presentation.
\end{abstract}

\section{Introduction}

Multiple myeloma (MM) is a rare hematological malignant pathology, but its incidence has increased over recent years (5-6 cases per 100,000 population). Therapeutic advances have increased the 5-year survival rate to around $70 \%[1]$. Patients rarely present with central nervous system (dural or extradural) involvement at diagnosis, with only a few such cases described in the literature [2]. MM can also be complicated with an acquired von Willebrand syndrome (VWS). Although von Willebrand disease is the most common hereditary hemorrhagic pathology (affecting up to $1 \%$ of the general population), the acquired form of VWS is an unusual complication of certain lymphoproliferative disorders, particularly MM [3].

\section{Case Presentation}

Here, we report the case of a 48-year-old Caucasian male with no previous relevant medical/surgical history, who was admitted to neurology services due to intermittent headaches, dysgeusia, and persistent dizziness for two months. His symptoms also included spontaneously resolving gum bleeding. An MRI was performed (Figure 1(a)), revealing a voluminous left extraparenchymal posterior fossa tumor, complicated by occipital osteolysis and hydrocephalus, without distant metastatic lesions. Computerized tomography (CT) scanning revealed no other suspicious lesion (Figure 1(b)).

A stereotaxic intracerebral biopsy was performed, and at the same time, a ventriculoperitoneal shunt was established to control intracranial hypertension. These procedures were complicated by a voluminous right parietal hematoma with mass effect and falcorial and temporal commitment, resulting in a secondary epileptic seizure. No hemostasis report was available before this intervention.

To explore this major bleeding, a hemostasis assessment was performed. This revealed a prolonged activated partial thromboplastin time (APTT) of $44 \mathrm{~s}$ (normal value (NV): 


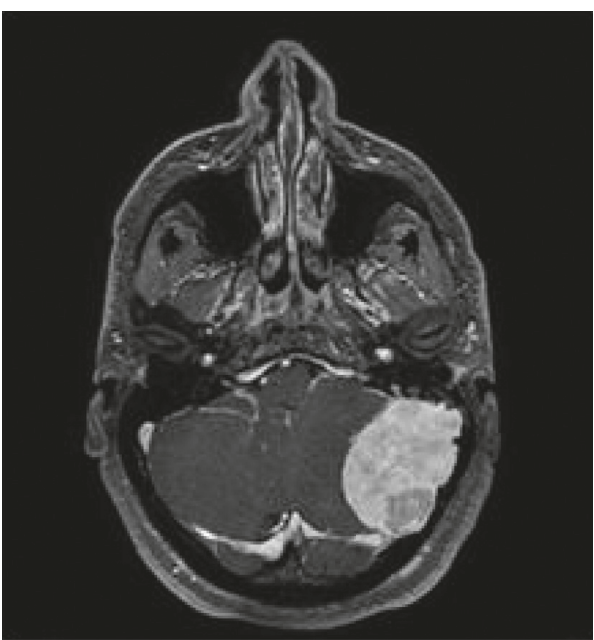

MRI at diagnosis:

Axial 3DT1 sequence with gadolinium injection. Well-limited mass, relatively homogeneous, with intense enhancement of extraparenchymal localization, pushing the left cerebellar hemisphere and compressing the 4 th ventricle.

(a)

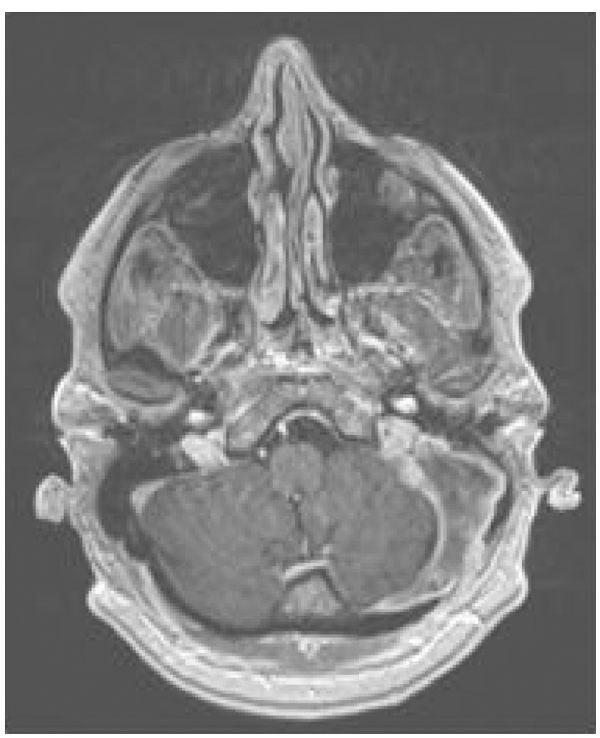

Axial 3DT1 sequence with gadolinium injection. Strong regression of left osteomeningeal mass syndrome with more necrotic appearance. Regression of the mass effect on the cerebellum

(c)

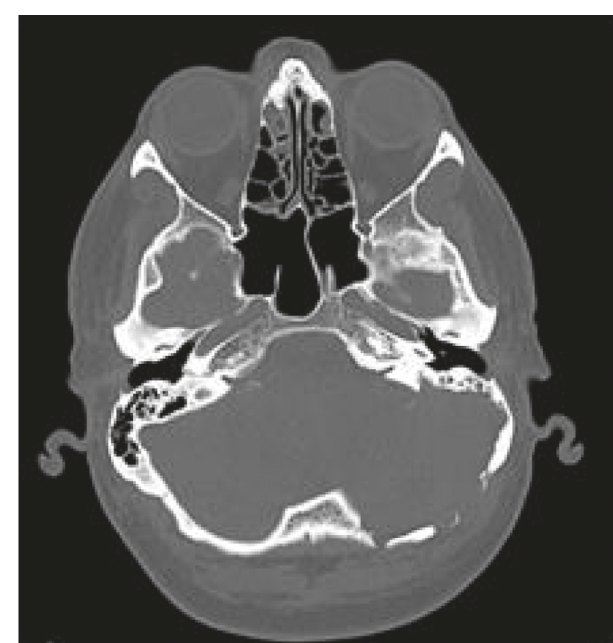

CT scan at diagnosis:

Osteomeningeal mass syndrome, lytic, centered on occipital bone and left mastoid

(b)

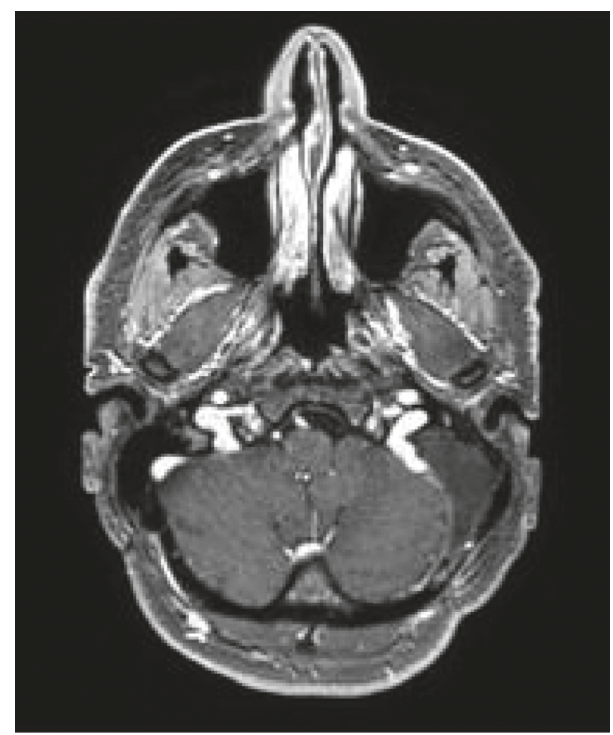

Axial 3DT1 sequence with gadolinium injection. Persistant regression of mass syndrome with disappearance of contrast enhancement. Disappearance of the mass effect on the cerebellum

(d)

FIgURE 1: (a) MRI at diagnosis. (b) CT scan at diagnosis. (c) Follow-up MRI after two courses of bortezomib, thalidomide, and dexamethasone. (d) Follow-up MRI after two courses of lenalidomide maintenance.

23-35 s) and a decreased factor VIII level (FVIII: 10\%; NV: $60-150 \%)$. In addition, the level of von Willebrand factor antigen was low (vWF: Ag $<10 \%$; NV $>60 \%$ ), and the activity of $\mathrm{vWF}$ ristocetin cofactor was severely decreased (vWF : RCo $<4 \%$, undetectable; $\mathrm{NV}>60 \%$ ), indicating an acquired von Willebrand syndrome (VWS).

Biological evaluation, including serum protein electrophoresis, revealed a monoclonal gammopathy IgG kappa of
$16 \mathrm{~g} / \mathrm{L}$, associated with high kappa-free light chain of $109 \mathrm{mg} / \mathrm{L}$ (NV, 3.3-19.4 mg/L). The lambda-free light chain level was $37.2 \mathrm{mg} / \mathrm{L}(\mathrm{NV}, 5.7-26.3 \mathrm{mg} / \mathrm{L})$, and the kappa/ lamba ratio was 2.94 (NV, 0.26-1. 65). Complete blood count (CBC), renal function, and corrected serum calcium were normal. We detected a Bence-Jones proteinuria, with global proteinuria of $1.73 \mathrm{~g} / \mathrm{L}$, and B2 microglobulin of $1.88 \mathrm{mg} / \mathrm{L}(\mathrm{NV}, 0.9-2 \mathrm{mg} / \mathrm{L})$. The albumin level was $12.3 \mathrm{~g} / \mathrm{L}$ 


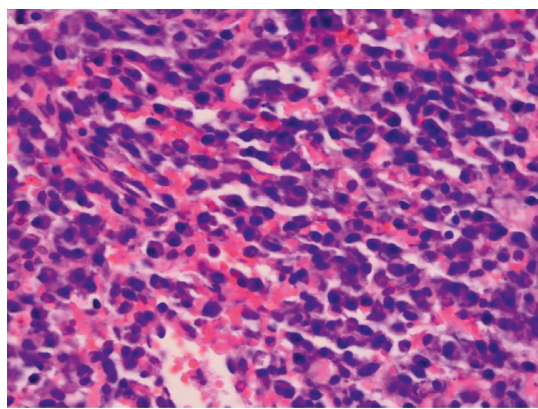

(a)

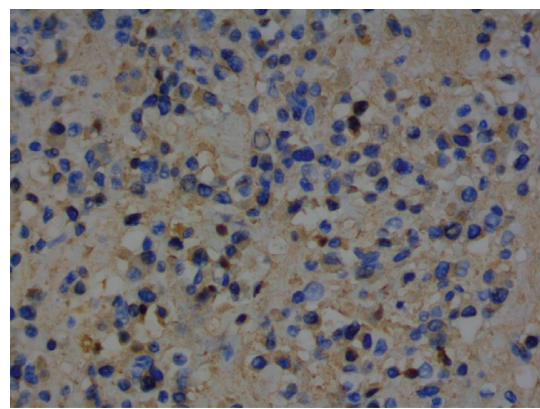

(b)

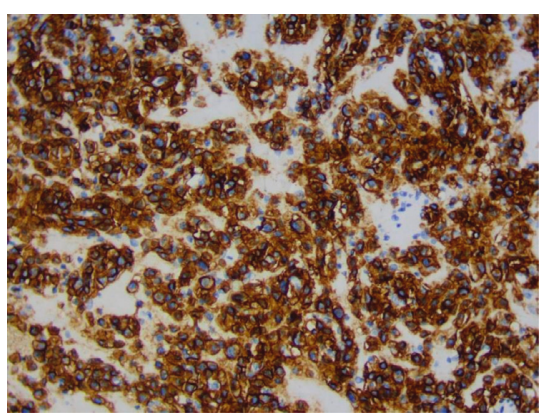

(c)

FIGURE 2: (a) Neoplastic plasma cell proliferation. Hematoxylin-eosin-saffron (HES) coloration, $\times 400$ magnification. (b) Monotypic plasma cell proliferation. Anti-kappa antibody, $\times 400$ magnification. (c) CD138 expression by plasma cells. Anti-CD138 antibody, $\times 400$ magnification.

(NV, 35-52 mg/L), and the LDH level was $265 \mathrm{U} / \mathrm{L}(\mathrm{NV}$, $<248 \mathrm{U} / \mathrm{L})$.

Histological examination of the biopsy supported a diagnosis of plasmacytoma (Figures 2(a)-2(c)), revealing the following atypical plasma cells proliferation markers: $\mathrm{CD} 38^{+}, \mathrm{MUM}^{-\mathrm{IRF}_{4}+}$, positive expression of kappa-free light chain (KP-53 clone) without expression of lambda-free light chain (K22-Y clone), $\mathrm{CD}^{-} 0^{-}, \mathrm{CD}^{-}$, and proliferation index ki67 of 5\%. Bone marrow aspiration showed 5\% atypical plasma cells. Serum and bone marrow immunophenotyping were not performed. Cytogenetic analysis supported the conclusion of a standard risk, without $t(4 ; 14)$ or del(17p). The revised prognostic score R-ISS was evaluated to be 2 .

Prior to myeloma confirmation, the initial case management comprised symptomatic treatment, including evacuation of intraparenchymal hematoma, and establishment of an external ventricular bypass. Immediately before this surgical intervention, FVIII was administered in association with VWF (KOVALTRY ${ }^{\circledR} 70 \mathrm{UI} / \mathrm{kg}+$ WILFACTIN $^{\circledR}$ $52 \mathrm{UI} / \mathrm{kg} \mathrm{UI}$ ). Immediately after surgical intervention, FVIII (KOVALTRY® ${ }^{\circledR} 70 \mathrm{UI} / \mathrm{kg}$ ) was administered without VWF. During the night, this treatment was switched to recombinant factor VII (NOVOSEVEN ${ }^{\circledR} 86 \mu \mathrm{g} / \mathrm{kg}$ ). FVIII treatment increased the circulating FVIII level to $59 \%$ with persisting low levels of vWF : Ag (11\%) and vWF : Rco (4\%). Administration of high-dose intravenous immunoglobulins (CLAYRIG ${ }^{\circledR} 0.8 \mathrm{mg} / \mathrm{kg}$ ) allowed the FVIII level to increase to $>200 \%$, with a vWF : Ag level of $68 \%$ and vWF : Rco level of $70 \%$, causing the bleeding to stop. The patient's FVIII and VWF levels remained normal for 3 weeks. At 3 weeks after the first infusion, VWF activity decreased to $55 \%$, with a vWF : Ag level of $120 \%$ and normal FVIII at 135\%, without bleeding event, necessitating another treatment with intravenous immunoglobulins before a new surgical intervention (laparoscopy) was required to eliminate peritonitis by infection of the external ventricular bypass valve. Subsequently, we observed normalization of hemostasis (FVIII > 150\%; VWF activity $>60 \%$; vWF : RCo $>60 \%$ ).

For symptomatic myeloma with extraparenchymal plasmacytoma developed at the expense of the occipital bone, the specific treatment started with 4 days of administration of $40 \mathrm{mg}$ of dexamethasone treatment alone. This was followed by the induction of four 28-day cycles of VTD plus bortezomib $1.3 \mathrm{mg} / \mathrm{m}^{2}$ on D1, D4, D8, and D11; thalidomide $100 \mathrm{mg}$ continuously; and dexamethasone $40 \mathrm{mg}$ on D1-D2, D8-D9, D15-D16, and D22-D23. After one cycle of VTD, the ventriculoperitoneal shunt could be removed. After two cycles, MRI showed regression of the plasmacytoma, which was considered complete (Figure 1(b)). After the third cycle, we observed a very good partial response, with nonmeasurable serum and urine M-proteins and normalization of the light chain ratio, as well as complete normalization of the hemostasis balance parameters.

The patient then received high-dose melphalan chemotherapy and autologous stem cell transplantation, followed by two VTD consolidation courses, and then maintenance with lenalidomide. After two courses of maintenance, MRI revealed a net decrease of the extraparenchymal posterior fossa tumor, with a greater necrotic aspect and less enhancement (Figure 1(c)). To date, our patient remains in VGPR without neurological symptoms after 4 months of maintenance. The patient is free of progression 14 months after their original presentation.

\section{Discussion}

To our knowledge, this is the first reported case of extraparenchymal intracranial plasmacytoma associated with acquired VWS. Kumar et al. [4] suggested that physiopathological mechanisms of acquired VWS are poorly understood, but its occurrence with malignant hematologic disorders, especially dysproteinemias, has been described. [5-11]. Acquired VWS is usually similar to the "2A" type inherited disease, in that it involves decreases of both the activity and concentration of vWF (vWF: RCo and vWF: Ag) [12]. In addition, type 1 or type 3 VWD can also be detected in individuals in whom acquired VWS is associated with abnormal synthesis of vWF (e.g., hypothyroidism) [12], and optimally, a multimeric analysis completes the diagnosis of acquired VWS. Acquired VWD in MM is based on several mechanisms: antibodies specifically directed against functional domains of VWF [11, 13], the monoclonal protein can also accelerate immunologic clearance of VWF [14], 
adsorption of VWF by malignant cells [15], and finally a GpIbmediated selective adsorption of VWF on malignant cells [16].

Intravenous immunoglobulin (IVIg) has shown efficacy for treatment of acquired VWS with type immunoglobulin (Ig) G monoclonal gammopathies of undetermined significance (MGUS) $[17,18]$. Such treatment can reportedly induce a prompt and sustained increase of FVIII/VWF activities and shorten the bleeding time for at least 15-20 days for all IgGMGUS with a correction of VWF multimeric structure [6]. Data from the International Society on Thrombosis and Hemostasis (ISTH) registry indicate that patients exhibiting acquired VWS along with lymphoproliferative disease (48\% of patients with acquired VWS) may also benefit from IVIg therapy $[6,18]$. Normalization of plasma vWF activity is usually observed no earlier than $24-48 \mathrm{~h}$ after IVIg administration. Thus, it was surprising and unusual that vWF: Ag and vWF: Rco increased immediately $(<8 \mathrm{~h})$ after IVIg administration in our present case.

With regard to intracranial extramedullary involvement, a recently reported series of 50 patients included 14 patients with dural or extradural involvement at diagnosis [2]. Of these patients, $78 \%$ exhibited spinal osteolytic abnormalities, which were not observed in our present patient. Of the 50 patients, 10 were able to benefit from an autotransplant, including 7 who exhibited complete remission/very good partial response. Multivariate analysis in that study revealed that survival was associated with B2 microglobulin levels and complete response or very good partial response. The median survival was 25 months among patients with plasmacytoma exhibiting dural or extradural involvement and was 46 months among MM patients without CNS involvement.

In conclusion, the survival of patients with multiple myeloma and extradural disease remains lower than that of other MM patients. However, new therapeutic options and reinforcement with autotransplant have yielded encouraging results. Our currently described patient presented with a serious initial disease associated with acquired VWS, but highly effective treatment led to regression of the symptoms without sequelae.

\section{Consent}

The patient gave consent for his case to be reported in a scientific manuscript.

\section{Conflicts of Interest}

The authors declare that there are no conflicts of interest regarding the publication of this paper.

\section{References}

[1] I. Turesson, M. Bjorkholm, C. H. Blimark, S. Kristinsson, R. Velez, and O. Landgren, "Rapidly changing myeloma epidemiology in the general population: increased incidence, older patients, and longer survival," European Journal of Haematology, vol. 101, no. 2, pp. 237-244, 2018.

[2] A. Gozzetti, A. Cerase, F. Lotti et al., "Extramedullary intracranial localization of multiple myeloma and treatment with novel agents: a retrospective survey of 50 patients," Cancer, vol. 118, no. 6, pp. 1574-1584, 2012.

[3] C. Dicke, S. Schneppenheim, K. Holstein et al., "Distinct mechanisms account for acquired von Willebrand syndrome in plasma cell dyscrasias," Annals of Hematology, vol. 95, no. 6, pp. 945-957, 2016.

[4] S. Kumar, R. K. Pruthi, and W. L. Nichols, "Acquired von Willebrand disease," Mayo Clinic Proceedings, vol. 77, no. 2, pp. 181-187, 2002.

[5] G. I. C. Ingram, P. J. Kingston, J. Leslie, and E. J. W. Bowie, "Four cases of acquired von Willebrand's syndrome," British Journal of Haematology, vol. 21, no. 2, pp. 189-199, 1971.

[6] A. B. Federici, F. Stabile, G. Castaman, M. T. Canciani, and P. M. Mannucci, "Treatment of acquired von Willebrand syndrome in patients with monoclonal gammopathy of uncertain significance: comparison of three different therapeutic approaches," Blood, vol. 92, no. 8, pp. 2707-2711, 1998.

[7] N. Jin, F. F. Salahuddin, and J. A. Nesbitt, "Acquired von Willebrand disease and multiple myeloma," Blood Coagulation and Fibrinolysis, vol. 25, no. 8, pp. 890-893, 2014.

[8] S. Katagiri, D. Akahane, K. Amano, and K. Ohyashiki, "Longterm remission of acquired von Willebrand syndrome associated with multiple myeloma using bortezomib and dexamethasone therapy," Haemophilia, vol. 22, no. 6, pp. e557-e559, 2016.

[9] B. M. Sampson, M. Greaves, R. G. Malia, and F. E. Preston, "Acquired von Willebrand's disease: demonstration of a circulating inhibitor to the factor VIII complex in four cases," British Journal of Haematology, vol. 54, no. 2, pp. 233-244, 1983.

[10] E. G. Bovill, W. B. Ershler, E. A. Golden, B. H. Tindle, and J. R. Edson, "A human myeloma-produced monoclonal protein directed against the active subpopulation of von Willebrand factor," American Journal of Clinical Pathology, vol. 85, no. 1, pp. 115-123, 1986.

[11] H. Mohri, J. Tanabe, M. Ohtsuka et al., "Acquired von Willebrand disease associated with multiple myeloma; characterization of an inhibitor to von Willebrand factor," Blood Coagulation and Fibrinolysis, vol. 6, no. 6, pp. 561-566, 1995.

[12] A. Mital, "Acquired von Willebrand syndrome," Advances in Clinical and Experimental Medicine, vol. 25, no. 6, pp. 1337-1344, 2016.

[13] H. Mohri, T. Noguchi, F. Kodama, A. Itoh, and T. Ohkubo, "Acquired von Willebrand disease due to inhibitor of human myeloma protein specific for von Willebrand factor," American Journal of Clinical Pathology, vol. 87, no. 5, pp. 663-668, 1987.

[14] O. Zettervall and I. M. Nilsson, "Acquired von Willebrand's disease caused by a monoclonal antibody," Acta Medica Scandinavica, vol. 204, no. 1-6, pp. 521-528, 2009.

[15] C. Richard, M. A. Cuadrado, M. Prieto et al., "Acquired von Willebrand disease in multiple myeloma secondary to absorption of von Willebrand factor by plasma cells," American Journal of Hematology, vol. 35, no. 2, pp. 114-117, 1990.

[16] M.-L. Scrobohaci, M.-T. Daniel, Y. Levy, J.-P. Marolleau, and J.-C. Brouet, "Expression of GpIb on plasma cells in a patient with monoclonal IgG and acquired von Willebrand disease," British Journal of Haematology, vol. 84, no. 3, pp. 471-475, 1993.

[17] A. Tiede, J. H. Rand, U. Budde, A. Ganser, and A. B. Federici, "How I treat the acquired von Willebrand syndrome," Blood, vol. 117, no. 25, pp. 6777-6785, 2011.

[18] A. B. Federici, "Use of intravenous immunoglobulin in patients with acquired von Willebrand syndrome," Human Immunology, vol. 66, no. 4, pp. 422-430, 2005. 


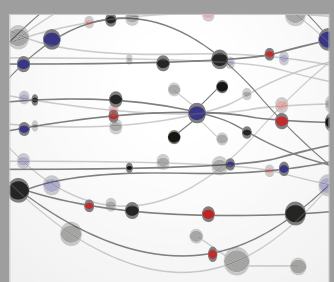

The Scientific World Journal
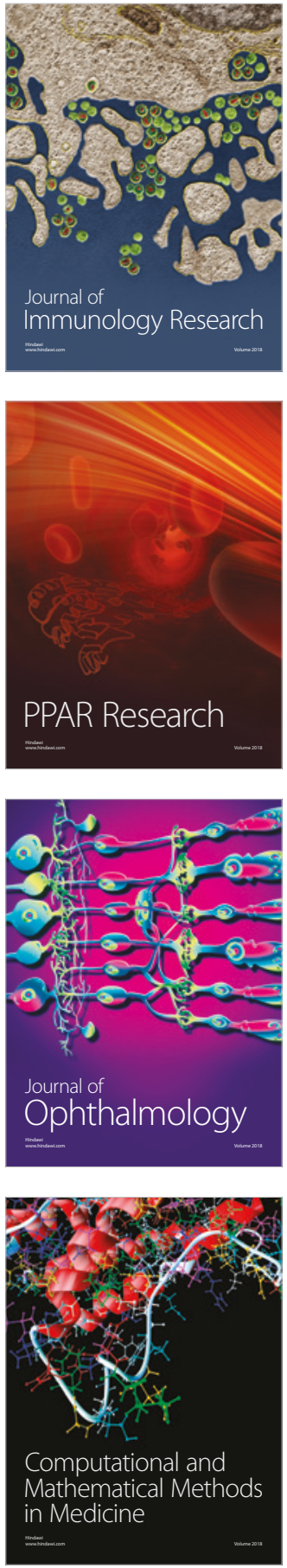

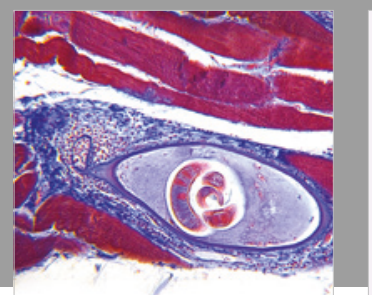

Gastroenterology Research and Practice

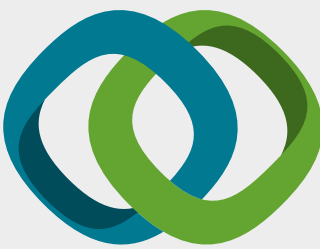

\section{Hindawi}

Submit your manuscripts at

www.hindawi.com
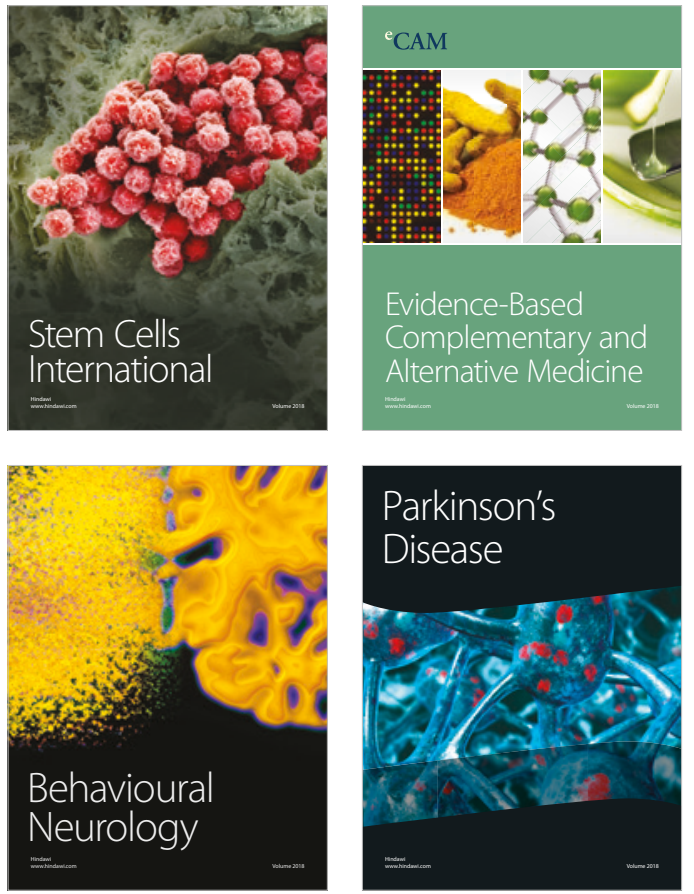

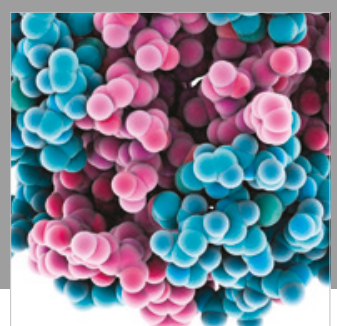

ournal of

Diabetes Research

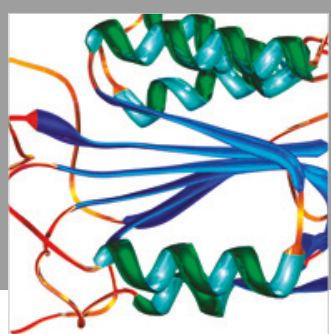

Disease Markers
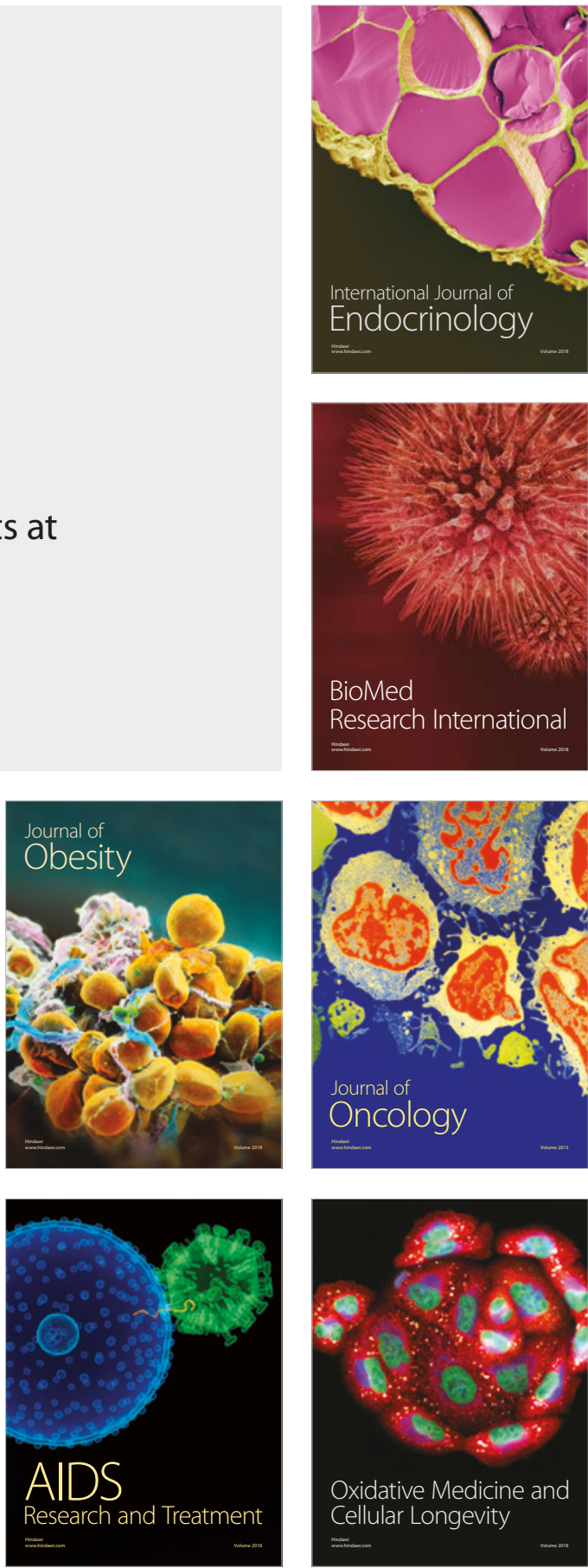